\title{
Sex-lethal imparts a sex-specific function to UNR by recruiting it to the msl-2 mRNA 3' UTR: translational repression for dosage compensation
}

\author{
Kent Duncan, ${ }^{1}$ Marica Grskovic, ${ }^{1,3}$ Claudia Strein, ${ }^{1}$ Karsten Beckmann, ${ }^{1}$ Ricarda Niggeweg, ${ }^{1}$ \\ Irina Abaza, ${ }^{2}$ Fátima Gebauer, ${ }^{2}$ Matthias Wilm, ${ }^{1}$ and Matthias W. Hentze ${ }^{1,4}$ \\ ${ }^{1}$ Gene Expression Unit, European Molecular Biology Laboratory, 69117 Heidelberg, Germany; ${ }^{2}$ Centre de Regulació \\ Genómica (CRG-UPF), 08003 Barcelona, Spain
}

\begin{abstract}
MSL-2 (male-specific lethal 2) is the limiting component of the Drosophila dosage compensation complex (DCC) that specifically increases transcription from the male $\mathbf{X}$ chromosome. Ectopic expression of MSL-2 protein in females causes DCC assembly on both $\mathrm{X}$ chromosomes and lethality. Inhibition of MSL-2 synthesis requires the female-specific protein sex-lethal (SXL), which binds to the msl-2 mRNA $5^{\prime}$ and $3^{\prime}$ untranslated regions (UTRs) and blocks translation through distinct UTR-specific mechanisms. Here, we purify translationally silenced msl-2 mRNPs and identify UNR (upstream of N-ras) as a protein recruited to the 3' UTR by SXL. We demonstrate that SXL requires UNR as a corepressor for 3'-UTR-mediated regulation, imparting a female-specific function to the ubiquitously expressed UNR protein. Our results reveal a novel functional role for UNR as a translational repressor and indicate that UNR is a key component of a "fail-safe" dosage compensation regulatory system that prevents toxic MSL-2 synthesis in female cells.
\end{abstract}

[Keywords: Translational control; dosage compensation; mRNP; cold shock domain; female cell line; sex-specific function]

Supplemental material is available at http://www.genesdev.org.

Received October 27, 2005; revised version accepted December 1, 2005.

As for many species, sex in Drosophila is determined by differential chromosome composition. Females have two $\mathrm{X}$ chromosomes, and males have only one $\mathrm{X}$ and a $\mathrm{Y}$ chromosome, leading to sex-specific gene expression that orchestrates sex-specific developmental programs (Cline and Meyer 1996). However, this situation also produces a twofold difference in the dose of all X-linked genes in the two sexes. Studies of aneuploidy show that differences in the dose of large blocks of genes are rarely compatible with viability (Birchler et al. 2005). Accordingly, many organisms have evolved essential "dosage compensation" mechanisms to equalize expression of Xlinked genes in both sexes (Nusinow and Panning 2005).

In Drosophila, dosage compensation of most X-linked loci occurs in males by increased transcription, and factors necessary for this process have a male-specific lethal (msl) mutant phenotype (Baker et al. 1994). These factors

${ }^{3}$ Present address: Program in Developmental and Stem Cell Biology, University of California, San Francisco, CA 94143, USA.

${ }^{4}$ Corresponding author.

E-MAIL hentze@embl.de; FAX 49-6221-387518.

Article and publication are at http://www.genesdev.org/cgi/doi/10.1101/ gad.371406. form a dosage compensation complex (DCC) in males, comprised of MSL-1, MSL-2, MSL-3, MLE, and MOF, and the noncoding RNAs roX1 and roX2. The DCC binds specifically to the male $\mathrm{X}$ chromosome and ultimately produces the twofold increase in transcription needed for dosage compensation (for review, see Gilfillan et al. 2004).

In female flies, MSL-2 is undetectable and MSL-1, MSL-3, roX1, and roX2 are also expressed at lower levels (Gilfillan et al. 2004). MSL-2 is the limiting component for DCC assembly, since forced high-level expression of MSL-2 in females stabilizes other DCC components, causing DCC loading onto X chromosomes and lethality (Kelley et al. 1995). Curiously, females express msl-2 mRNA, although levels are reduced to $20 \%-30 \%$ relative to males. Inhibition of msl-2 mRNA translation is therefore critical to prevent inappropriate synthesis of the toxic MSL-2 protein (Zhou et al. 1995; Bashaw and Baker 1997; Kelley et al. 1997).

MSL-2 protein production in females is blocked by the female-specific RNA-binding protein sex-lethal (SXL), the "master regulator" of somatic sex determination and dosage compensation (Cline 1978; Bell et al. 1988; for 
review, see Penalva and Sanchez 2003). SXL binds to poly $(\mathrm{U})$ stretches present in an intron in the msl-2 5' untranslated region (UTR), which is thereby retained in the mRNA. Subsequently, SXL proteins bound to sites in both the $5^{\prime}$ and the $3^{\prime}$ UTR cooperate to inhibit translation initiation (Bashaw and Baker 1997; Kelley et al. 1997; Gebauer et al. 1998, 1999, 2003).

We recently found that $5^{\prime}$ - and 3'-UTR-bound SXL complexes operate independently, targeting different steps of translation initiation (Beckmann et al. 2005). Unlike the 5'-UTR-regulatory region, 3'-UTR sequences adjacent to the SXL-binding sites (referred to here as "region 2456") are required for 3'-UTR-mediated translational repression, although they seem not to affect SXL binding (Gebauer et al. 2003). UV cross-linking and translation competition experiments implicated a titratable, high-molecular weight factor in 3'-UTR-mediated translational repression (Grskovic et al. 2003).

Here we report the discovery of this elusive factor. Using a novel method to purify translationally silenced msl-2 mRNPs, we identify the Drosophila homolog of mammalian UNR (upstream of N-ras) as the protein recruited to the msl-2 mRNA 3' UTR by SXL in a region 2456-dependent manner. We demonstrate that UNR acts as an obligatory cofactor for 3'-UTR-mediated translational repression, and show that SXL recruits UNR to the 3' UTR of msl-2 mRNA specifically in female cells, thereby imparting a sex and mRNA-specific translational repression function to UNR.

\section{Results}

Drosophila UNR specifically associates with the 3' UTR of translationally silenced msl2-mRNPs in a SXL-dependent manner

To identify proteins specifically associated with translationally silenced msl-2 mRNA, we modified the "Glutathione RNA (GRNA) Affinity Chromatography" approach (Czaplinski et al. 2005). Box-B hairpin sequences were inserted into the $3^{\prime}$ UTR of msl-2-derived RNAs expected to bind the native regulatory complex (Fig. 1A, BSEF, 3'EF); and control RNAs that we hypothesized should not [Fig. 1A, BmS(EF)m, mut2456; Grskovic et al. 2003]. All box-B-containing RNAs were confirmed to be regulated identically to the analogous RNAs without box-B (data not shown). Native mRNP complexes were assembled on box-B-containing RNAs under translation
A

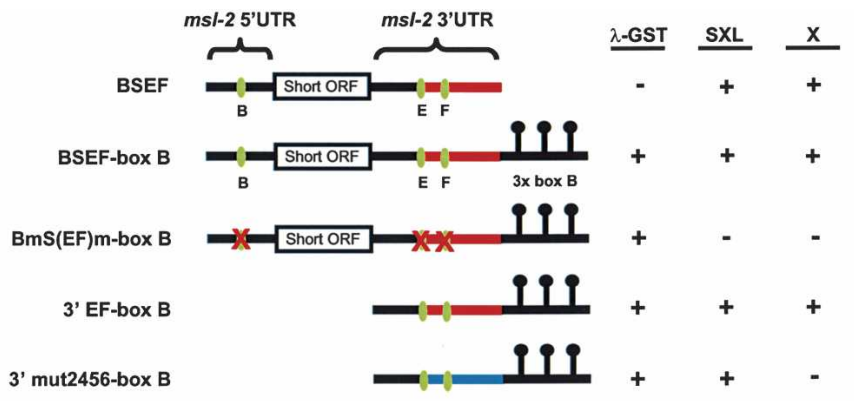

B

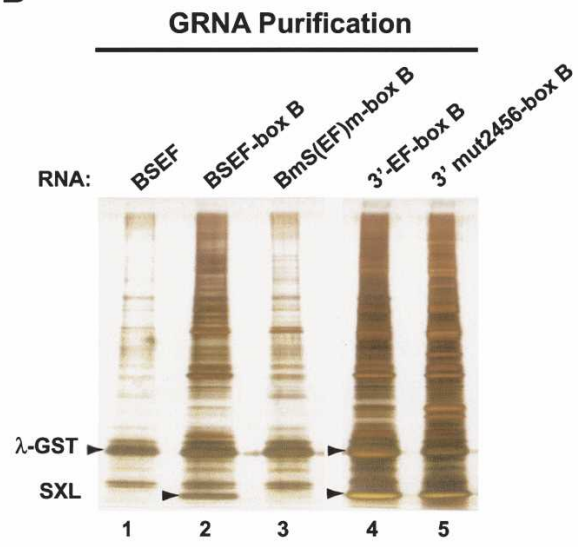

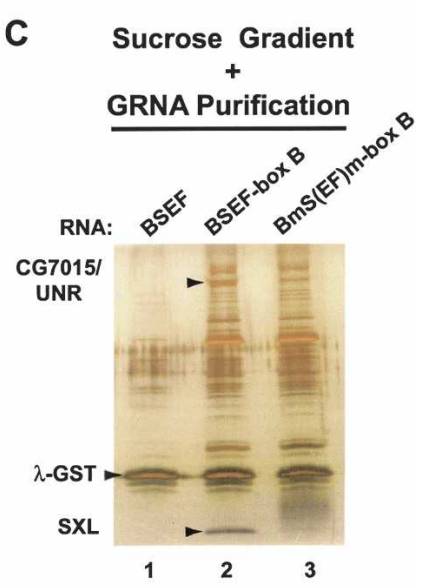

Figure 1. GRNA chromatography identifies CG7015/Drosophila UNR as a candidate msl-2 mRNA translational corepressor. (A) RNAs used for GRNA chromatography are depicted schematically and their expected associations are indicated. (B) RNAs were incubated in Drosophila embryo translation extracts to assemble silenced RNPs (lanes 2,4) or control nonsilenced RNPs (lanes 3,5 ) and were subsequently purified by GRNA chromatography. Lane 1 contains the negative control BSEF RNA without the box-B sequence. Eluates were separated by SDS-PAGE and silver stained to identify bands unique to silenced RNPs. Each silenced RNP and corresponding nonsilenced control lane was divided into $\sim 20$ subregions, and peptides from each were identified by mass spectrometry. (C) Sucrose density gradient fractionation of RNPs was performed and fractions containing repressed heavy mRNPs (Beckmann et al. 2005) (lane 2) or corresponding fractions from control samples (lanes 1,3) were pooled prior to GRNA chromatography. Arrowheads indicate CG7015/UNR, $\lambda$-GST, and SXL. (D) BSEFbox-B (lanes 3,4) or BmS(EF)m-box-B (lanes 5,6) RNAs were incubated in embryo extracts in the presence or absence of added recombinant SXL as indicated. GRNA eluates were normalized for RNA isolation efficiency and analyzed by SDSPAGE and immunoblotting with anti-UNR antibodies. 
conditions in Drosophila embryo extracts, purified by GRNA chromatography, and separated by SDS-PAGE (Fig. 1B). Proteins contained within BSEF or 3'EF RNPs and absent from corresponding regions from negative control lanes were identified by mass spectrometry and are shown in Table 1. We also isolated the repressed "heavy RNP" described for 3'-UTR-mediated inhibition (Beckmann et al. 2005) by sucrose density gradient centrifugation, followed by GRNA chromatography. This procedure reduced the complexity of the purified RNP, and identified ORF CG7015 as the only protein that is highly enriched in wild-type BSEF-box-B mRNP eluates (Fig. 1C, lane 2).

Sequence analysis of ORF CG7015 revealed significant similarity to the previously characterized mammalian protein UNR. This was surprising for a putative translational corepressor, because mammalian UNR, a cytoplasmically localized RNA-binding protein (JacqueminSablon et al. 1994), stimulates translation of both viral and cellular internal ribosome entry site (IRES) containing mRNAs (Hunt et al. 1999; Boussadia et al. 2003; Evans et al. 2003; Mitchell et al. 2003; Brown and Jackson 2004; Tinton et al. 2005). UNR is also a major regulator of translationally coupled mRNA turnover mediated by the c-fos mCRD RNA element (Grosset et al. 2000; Chang et al. 2004).

UNR has five cold-shock nucleic acid-binding domains (Jacquemin-Sablon et al. 1994; Graumann and Marahiel 1998), each with the unique substitution of the sequence FFH for the canonical FVH in part of the RNAbinding surface (Doniger et al. 1992). CG7015 also has five cold-shock domains (CSDs) with the signature FFH motif (Fig. 2). Overall sequence identity between CG7015 and human UNR is $~ 45 \%$, and this is higher within the CSDs $170 \%, 56 \%, 51 \%, 53 \%$, and $66 \%$ identity for CSD-1-CSD-5, respectively). The Drosophila genome encodes no other protein with similarly high sequence identity to mammalian UNR, and we therefore conclude that ORF CG7015 is Drosophila UNR and refer to it as "UNR" hereafter.

To assess the SXL dependence of UNR association with msl-2 mRNA, we analyzed GRNA chromatography eluates by immunoblotting with antibodies raised

Table 1. Copurifying proteins identified by mass spectrometry

\begin{tabular}{lll}
\hline $\begin{array}{l}\text { Molecular } \\
\text { weight (kDa) }\end{array}$ & $\begin{array}{l}\text { FlyBase } \\
\text { annotation }\end{array}$ & Name/description \\
\hline 134.3 & CG30149 & Rigor mortis \\
116.6 & CG7015 & UNR (this study) \\
78.6 & CG10279 & Rm62 \\
75.8 & CG6203 & dFMR1 \\
75.1 & CG9412 & Rasputin \\
49.2 & CG4916 & Me31B \\
44.8 & CG10922 & La \\
37.0 & CG5654 & Y-box protein \\
\hline
\end{tabular}

Predicted molecular weight, FlyBase annotation, and the name and/or description matching proteins specifically identified in Figure 1B (lanes 2,4) are provided. against Drosophila UNR. Addition of recombinant SXL to the embryo extracts strongly stimulates the association of UNR specifically with the wild-type reporter (Fig. $1 \mathrm{D}$, cf. lanes 3,4 and 5,6). A low level of UNR also associates with the wild-type BSEF-Box-B RNA in the absence of added SXL, (Fig. 1D, lane 3), most likely due to endogenous SXL in the extract. Taken together with the mass spectrometry results, these data show that SXL recruits UNR to the $3^{\prime}$ UTR of msl-2 mRNA, and that recruitment requires region 2456.

An in vivo cell model for translational control of msl-2 mRNA

The biochemical data strongly implicated UNR as the elusive 3'-UTR corepressor recruited by SXL. For functional analysis of UNR's potential role as a $3^{\prime}$-UTR corepressor, we sought a female cell line expressing SXL, reasoning that this approach offered several advantages. First, it would enable use of an RNA interference (RNAi) strategy for evaluating the contribution of UNR to msl-2 mRNA translational control in the presence of the correct female concentration of SXL relative to other factors. Second, it would permit analysis of the functional effects of depleting UNR on endogenous msl-2 mRNA and MSL-2 protein levels. Finally, because UNR deficiency is embryonic lethal in the mouse (Boussadia et al. 1997), Drosophila UNR may also have an essential function in both sexes unrelated to dosage compensation. Thus, analyzing function in cell culture might circumvent pleiotropic and/or lethal effects that could confound analysis of phenotypes in whole flies.

Drosophila Kc cells (Echalier 1971) consist primarily of diploid XX cells (Dolfini 1971) and splice endogenous doublesex mRNA in the female mode (Burtis and Baker 1989). Importantly, they also express SXL, whereas MSL-2 is barely detectable in these cells (Fig. 3A, lane 4; S. Mendjan, M. Taipale, J. Kind, H. Holz, P. Gebhardt, M. Schelder, M. Vermeulen, A. Buscaino, K. Duncan, J. Meuller, et al., in prep.). Depletion of SXL by RNAi induces endogenous MSL-2 protein expression to levels comparable to male SL-2 cells (Fig. 3A, lanes 1,8). Endogenous msl-2 mRNA levels also increase about fourfold in SXL-depleted Kc cells (Supplementary Fig. S1A). However, as for female flies (Zhou et al. 1995; Bashaw and Baker 1997; Kelley et al. 1997), this difference is much smaller than the effect on MSL-2 protein levels (Fig. 3A), reflecting a strong translational component in the regulation of MSL-2 expression by SXL in Kc cells. We also detected low levels of MSL-1, roX1, and roX2 in Kc cells, and these levels increase strongly after SXL depletion (Supplementary Fig. S1B-E). Thus, regulation of all analyzed DCC components by SXL in Kc cells is strikingly similar to that previously reported for female flies (Hilfiker et al. 1994; Palmer et al. 1994; Bashaw and Baker 1995; Kelley et al. 1995; Zhou et al. 1995; Meller et al. 1997; Franke and Baker 1999).

To determine the relative contribution of the $5^{\prime}$ and $3^{\prime}$ UTRs to translational inhibition of MSL-2 protein synthesis by endogenous SXL, we treated Kc cells with 

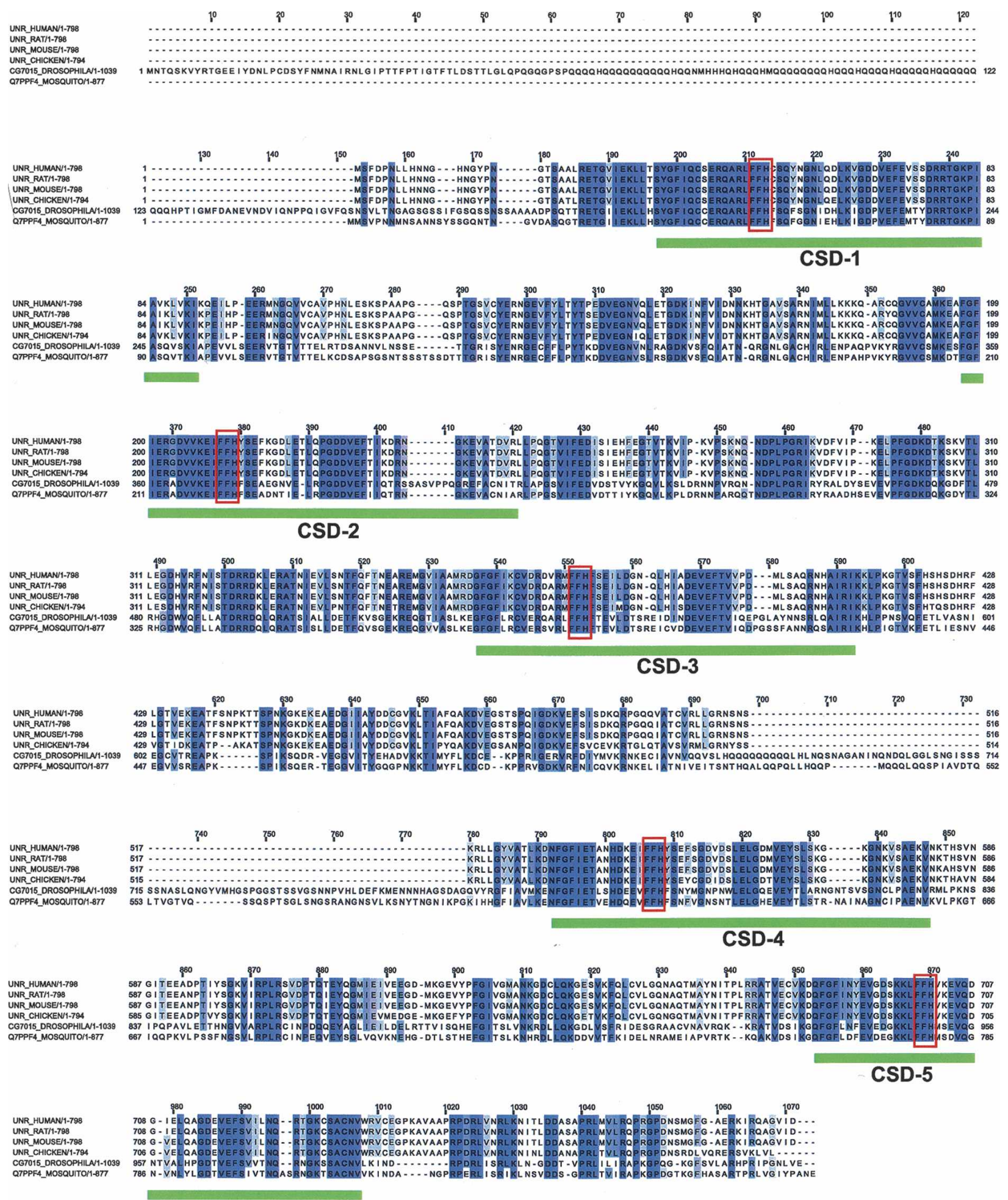

Figure 2. ORF CG7015 is Drosophila UNR. ORF CG7015 was aligned with UNR orthologs from a variety of species using ClustalW (EBI). Darker color indicates a higher degree of conservation of a specific residue. The five CSDs are underlined in green (CSD-1CSD-5). Red boxes highlight the FFH sequence in the RNP-2 consensus that is a signature of UNR CSDs.

double-stranded RNAs (dsRNAs) targeting SXL or GFP as a negative control. Subsequently, these cells were transfected with msl-2 reporter constructs containing the $\beta$-galactosidase ORF flanked by either wild-type msl-2 5' and 3' UTRs (wild type), or mutant SXL-binding sites in the $5^{\prime}$ UTR (5'mut), 3' UTR ( $3^{\prime}$ 'mut), or both $\left(5^{\prime}+3^{\prime}\right.$ mut) (Fig. 3B). In Kc cells treated with GFP dsRNA, activities of the $5^{\prime}$ mut, $3^{\prime}$ mut, and $5^{\prime}+3^{\prime}$ mut 
Figure 3. Endogenous SXL in Kc cells represses msl-2 mRNA translation via $5^{\prime}$ - and 3'-UTR SXL-binding sites. (A) Relative levels of MSL-2, SXL, or control $\alpha$-tubulin in whole-cell lysates from SL-2 cells (lanes 1-3), Kc cells (lanes 4-6), control GFP dsRNA-treated Kc cells (lane 7), or SXL dsRNA-treated cells (lane 8) were analyzed by immunoblotting. (B) msl-2- $\beta$-gal reporter constructs are depicted schematically. The HSP70 promoter and SV40 poly(A) sequence that combine to give low-level constitutive expression are indicated. Solid black lines represent sequences derived from the msl-2 5' and 3' UTRs, as indicated. SXL-binding sites $\mathrm{A}-\mathrm{F}$ are shown as green ovals. Region 2456 is shown in red. (C) Relative $\beta$-gal activity of Kc cells treated with the indicated dsRNAs and transfected with the indicated reporter constructs. All values were normalized to Renilla luciferase (Rluc) activity from a cotransfected plasmid to correct for any variations in transfection efficiency. Wild-type (WT) construct average activity in control GFP RNAi cells was set to 1.0. Average values and standard deviations in at least four independent RNAi experiments are shown. (D) Relative mRNA levels for transfected samples were analyzed by qPCR. msl-2- $\beta$-gal reporter values were normalized to Rluc mRNA levels. For each reporter, levels in SXL-depleted samples are shown relative to levels in the corresponding control GFP dsRNA-treated cells. Average values and standard deviations correspond to at least three independent RNAi experiments used for reporter activity analysis in $C$.
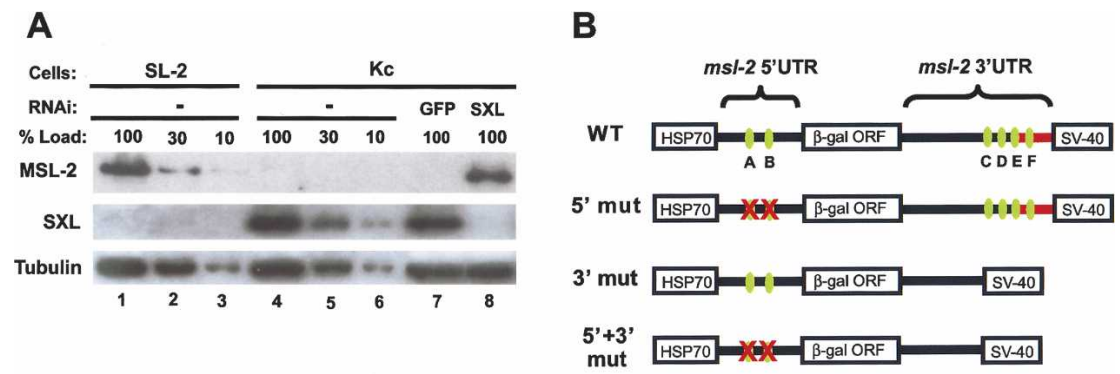

\section{C}
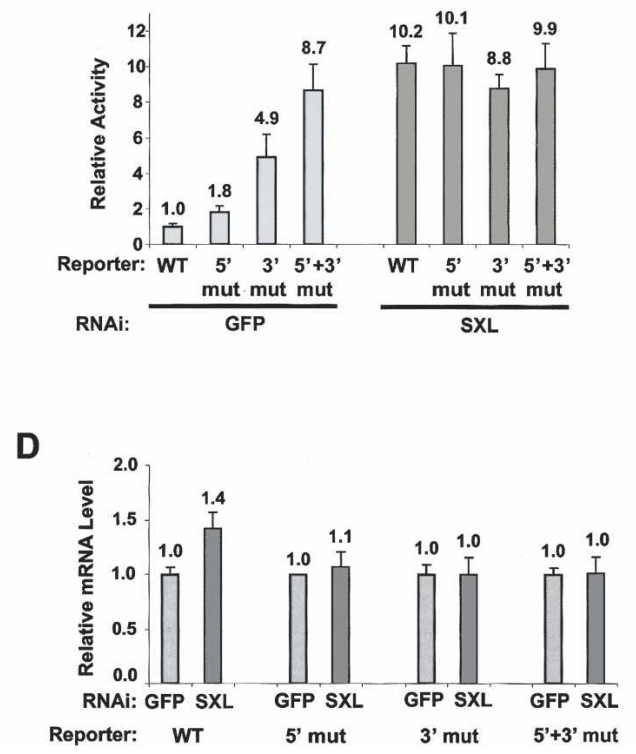

reporters were, respectively, approximately two-, five-, and ninefold higher than wild-type reporter activity, reflecting the contribution of both UTRs to repression in these cells (Fig. 3C). This pattern is identical in transfections of untreated Kc cells, indicating that it is not influenced unspecifically by the RNAi treatment (data not shown). Depletion of SXL brings the wild-type, 5'mut and 3 'mut reporter activity levels to essentially the same level as the $5^{\prime}+3^{\prime}$ mut construct, while displaying only a minor effect on mRNA levels relative to the GFP control RNAi cells (Fig. 3C,D). We conclude that endogenous SXL in Kc cells represses translation of msl-2 mRNA through $5^{\prime}$ - and 3'-UTR-binding sites, and that the effect of SXL depletion on endogenous msl-2 mRNA levels (Supplementary Fig. S1A) is separable from its role in translational control through the msl-2 $5^{\prime}$ and $3^{\prime}$ UTRs. Kc cells thus recapitulate the key aspects of regulation of MSL-2 expression by SXL in female flies, making them a useful model for analysis of MSL-2 translational control in vivo.

UNR and SXL corepress msl-2 reporter mRNAs via the msl-2 mRNA 3' UTR

To determine whether UNR functions as a corepressor of msl-2 mRNA translation, we depleted UNR by RNAi in
Kc cells and analyzed the effect on msl-2- $\beta$-gal reporter activities and mRNA levels. UNR depletion increased the relative activity of the wild-type and 5 ' mut reporters, whereas neither the $3^{\prime}$ mut nor $5^{\prime}+3^{\prime}$ mut reporter was significantly affected (Fig. 4B). Importantly, depletion of $>90 \%$ of UNR had no effect on SXL levels (Fig. 4A, cf. lanes $4,7,9$ ), showing that derepression of the wild-type and 5 'mut reporters does not result from an indirect effect on SXL expression. Thus, UNR depletion in female cells significantly and specifically increases the relative activity of msl-2 reporters containing 3'-UTR-binding sites for SXL.

We also analyzed the combined effect of simultaneous depletion of both SXL and UNR on reporter activity in a cell-based epistasis test. Codepletion was as efficient as the respective individual depletions (Fig. 4A) and SXL is clearly epistatic to UNR in this assay; there is no additional increase in relative reporter activity when UNR is codepleted (Fig. 4C). These data indicate that SXL function is necessary to see an effect of UNR depletion on the wild-type and 5'mut msl-2- $\beta$-gal reporters, strongly suggesting that these effects are SXL-dependent.

To confirm that the observed effects are translational, we analyzed the steady-state levels of reporter mRNAs 


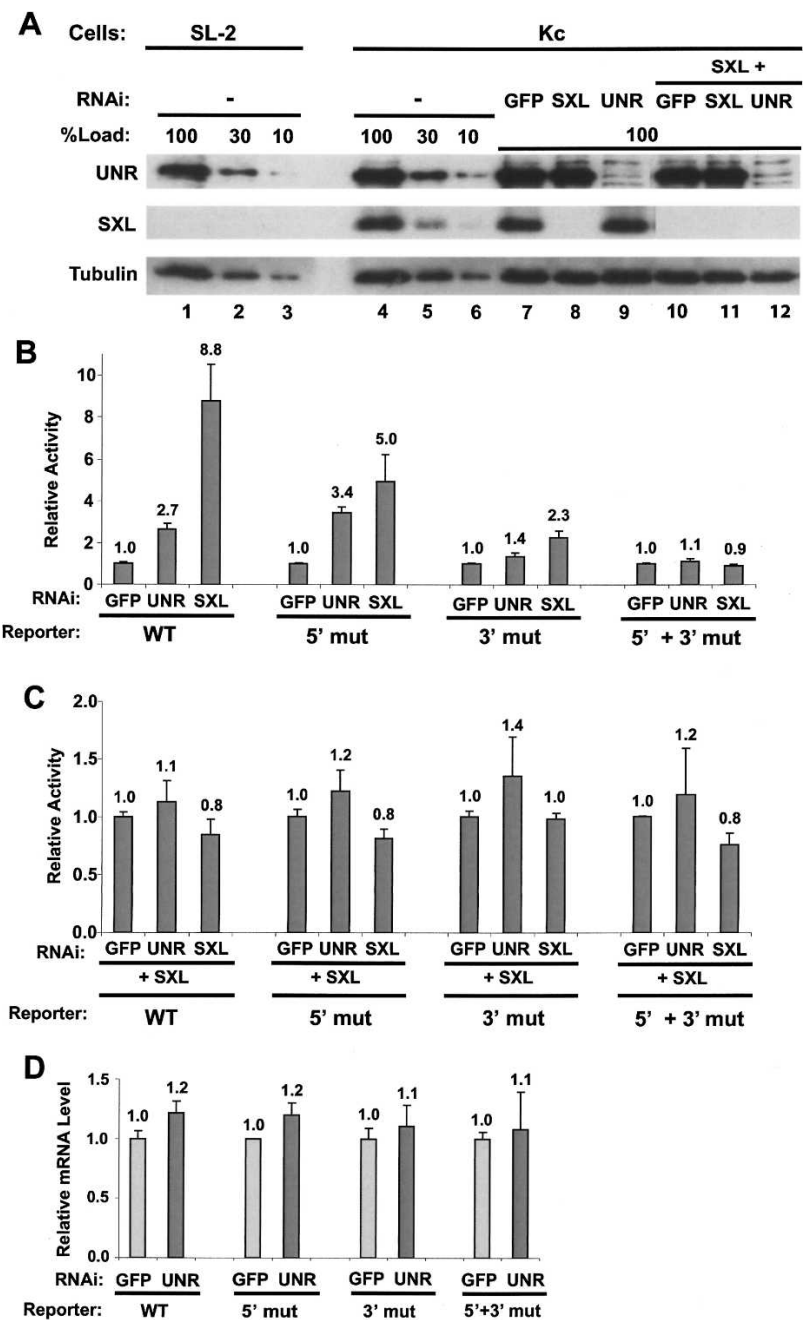

Figure 4. UNR acts as a $3^{\prime}$-UTR corepressor in conjunction with SXL. (A) Whole-cell extracts were prepared from mocktreated SL-2 cells (lanes 1-3), mock-treated Kc cells (lanes 4-6), or Kc cells treated with dsRNAs targeting EGFP (lane 7), SXL (lane 8), UNR (lane 9) alone, or in combination with SXL dsRNAs (lanes 10-12, respectively). Relative levels of UNR, SXL, and control $\alpha$-tubulin were determined by immunoblotting. $(B, C)$ Kc cells were treated with the indicated dsRNAs and subsequently transfected with wild-type (WT), 5' mut, 3' mut, or $5^{\prime}+3^{\prime}$ mut reporters, as indicated. Relative $\beta$-gal activities were normalized to Rluc as in Figure 3C. For each reporter, the level of expression in GFP-treated cells is set to 1.0, and the fold increase in expression in the UNR and/or SXL RNAi-treated cells is shown. Average values and standard deviations in at least four $(B)$ or two $(C)$ independent RNAi experiments are shown. $(D)$ Relative mRNA levels in the transfected samples were analyzed by qPCR as in Figure 3. For each reporter, the mRNA level in UNR-treated samples is shown relative to the amount in the corresponding GFP-treated samples, which is set to 1.0. Average values and standard deviations in at least three independent RNAi experiments are shown.

by qPCR. UNR depletion did not affect the steady-state level of any of these mRNAs (Fig. 4D). We conclude that UNR is required for $3^{\prime}$-UTR-mediated translational inhibition of the msl2 mRNA.
UNR is expressed in both female Kc and male SL-2 cells at similar levels (Fig. 4A). Thus, the contribution of UNR to translational inhibition of reporter mRNAs containing the wild-type msl-2 3' UTR could be specific to female cells or might occur in both male and female cells. To determine whether UNR's effects on MSL-2 expression are sex specific, and to more rigorously examine their SXL dependence, we depleted UNR by RNAi from phenotypically male SL-2 cells (Ryner and Baker 1991; Buscaino et al. 2003), which do not express endogenous SXL (Figs. 3A, 4A), and examined the effect on relative $m s 1-2$ reporter activities in the presence or absence of exogenously introduced SXL.

In the absence of SXL, the wild-type and $5^{\prime}+3^{\prime}$ mut msl-2- $\beta$-gal reporters display equal relative activities in SL-2 cells, and no specific effect of UNR depletion as compared with the GFP dsRNA-treated negative control is observed (Fig. 5A,C). This shows that UNR by itself fails to repress translation. Consistent with previous reports (Bashaw and Baker 1997), forced expression of SXL selectively reduces the activity of the wild-type reporter by $\sim 10$-fold (Fig. 5B). As expected, this effect is abrogated by depletion of the exogenous SXL. Importantly, the activity of the wild-type reporter, but not the $5^{\prime}+3^{\prime}$ mut reporter, in SXL-expressing SL-2 cells is specifically increased by threefold relative to the GFP control when UNR is depleted prior to transfection (Fig. 5B,C). Note that the relative increase in wild-type reporter activity in UNR-depleted cells is not due to increased mRNA levels (Fig. 5D).

Together with the results from Kc cells, these data demonstrate that both UNR and SXL are required as translational corepressors via the 3' UTR of msl-2 mRNA, and that neither of the two proteins can exert this function on its own. Thus, UNR, a protein that is present in approximately equal amounts in both male and female cultured embryonic cells (Fig. 4A) and flies (Abaza et al. 2006), acquires a sex-specific function in msl-2 mRNA translational inhibition when SXL is present.

$U N R$ is a bona fide corepressor of endogenous msl-2 $m R N A$ translation

To directly test whether UNR represses translation of endogenous msl-2 mRNA in Kc cells, we assessed MSL-2 protein and mRNA levels in Kc cells depleted of UNR by RNAi. Specific UNR depletion (Fig. 6A) clearly derepresses MSL-2 protein expression in comparison to untreated or GFP dsRNA-treated controls, for which MSL-2 was barely detectable (Fig. 6B). No additional increase in MSL-2 protein expression above that already observed with SXL depletion is observed when UNR and SXL are codepleted, implying that this effect is SXL dependent (data not shown). Importantly, endogenous msl-2 mRNA levels are unaffected in UNR-depleted cells (Fig. 6C). These data validate UNR as a bona fide translational corepressor necessary for tight inhibition of endogenous msl-2 mRNA translation by SXL in female cells. 
Figure 5. SXL recruits UNR for a sex-specific function. (A) Relative levels of msl-2- $\beta$-gal reporter activity in SL-2 cells treated with the indicated dsRNAs and transfected with either wild type (WT, light bars) or 5' + 3' mut (dark bars) reporters in the absence of SXL. Rlucnormalized activities of both reporters are compared with the $5^{\prime}+3^{\prime}$ mut reporter, which is set to $100 \%$ for each dsRNA treatment. $(B)$ Relative reporter activities in cells cotransfected with pHSP70-SXL. (C) UNR and $\alpha$-tubulin levels in duplicate samples from wildtype (WT) reporter-transfected, UNR dsRNAtreated (lanes 1-4), or EGFP dsRNA-treated (lanes 5-8) cells were analyzed by immunoblotting. $(D)$ RNase Protection Assay analysis of relative mRNA levels in untreated cells (lanes 1-9) or UNR dsRNA-treated cells (lanes 10-13), transfected with an actin5C promoter-LacZpositive control (lanes 1,2), no plasmid (lanes 3-5), wild-type (WT) reporter (lanes 6,8,10,12), or $5^{\prime}+3^{\prime}$ mut reporter (lanes $7,9,11,13$ ).
A

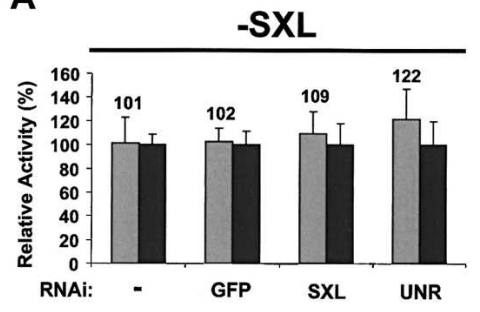

C

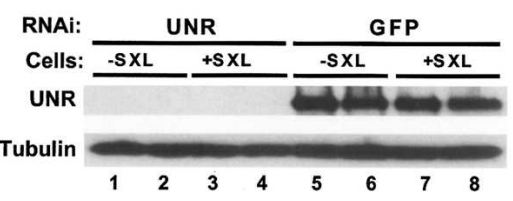

B

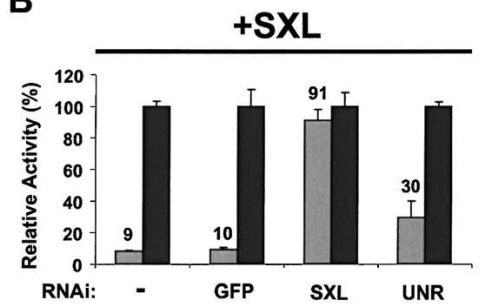

D

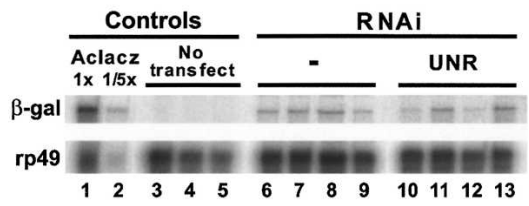

\section{Discussion}

Genetic approaches in Drosophila have proved powerful for identifying molecular components of developmental regulatory networks and for dissecting their functional interactions in vivo. Genetic analysis of sex-specific lethal mutations yielded the MSL proteins that are essential for dosage compensation in males (Belote and Lucchesi 1980; Uchida et al. 1981; Hilfiker et al. 1997), and SXL, the female-specific "master regulator" essential for female sexual development and negative regulation of the dosage-compensation machinery (Cline 1978; Bell et al. 1988). Here we identify a novel component of the dosage-compensation regulatory machinery that has eluded genetic methods. Using an mRNP purification approach and functional analysis, we demonstrate that the Drosophila UNR protein is recruited to msl-2 mRNA 3' UTR by SXL for translational inhibition of msl-2 mRNA specifically in female cells. Our data indicate that SXL imparts a female-specific translational repressor function to UNR, and imply that this novel function of UNR is critical for negative regulation of the dosage compensation machinery to prevent toxic effects in female cells.

$U N R$ is a specific corepressor of msl-2 mRNA translation in female cells

Previous results implied that region 2456 of the msl-2 mRNA was important for translational regulation via the 3' UTR (Grskovic et al. 2003). Since this region flanks the SXL-binding sites, it was hypothesized to bind a putative corepressor that acts in conjunction with SXL. We used GRNA chromatography in combination with sucrose-density gradient centrifugation to purify this factor, identifying Drosophila UNR (Fig. 1). Functional analyses of msl-2 reporter genes and endogenous msl-2 expression in female and male cell lines demonstrate that UNR is necessary for translational repression of msl-2 mRNA by SXL via the 3' UTR, but does not affect msl-2 mRNA translation in the absence of SXL. Taken together, our results show that UNR is a cofactor for translational repression of MSL-2 protein synthesis, specifically in female cells. Our conclusions are strongly supported by the results of Abaza et al. (2006), who independently isolated UNR using a different approach and could demonstrate that direct interaction of UNR with SXL helps recruit UNR to the msl-2 3' UTR and is critical for translational inhibition of $m s l-2$ reporter mRNAs by SXL in vitro. To our knowledge, this is the first time that a translational corepressor has been identified by a combined strategy of gradient and specific mRNP purification, and we anticipate that this method will prove useful as a general strategy.

Our analysis of msl-2- $\beta$-gal reporters further supports the recently proposed dual-mechanism model for msl-2 mRNA translational inhibition (Beckmann et al. 2005), which predicts that $3^{\prime}$-UTR corepressors should be required exclusively for 3'-UTR-mediated inhibition. Indeed, UNR depletion only affects msl-2 reporters with wild-type 3' UTRs significantly, and the strongest effect is on the $5^{\prime}$ mut reporter, where all regulation must occur through the 3' UTR. In this case, the quantitative effect of UNR depletion approaches the effect of SXL depletion (Fig. 4B). Since RNAi produces a "knockdown" effect that likely reflects a partial-loss-of-function rather than true null phenotype, differences in RNAi efficiency and/ or differences in relative concentrations of UNR and SXL necessary for inhibition may explain why the 5 'mut reporter is still slightly repressed after UNR knockdown. In any case, the in vivo analysis presented here directly supports the concept of independent regulatory contributions of $5^{\prime}$ - and $3^{\prime}$-UTR SXL complexes, and implies that UNR is a critical component for $3^{\prime}$-UTR-mediated inhibition. 
A

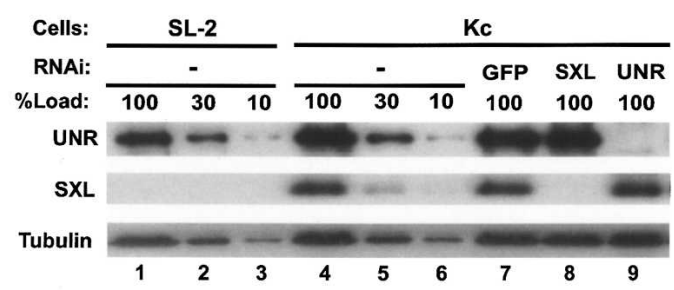

B

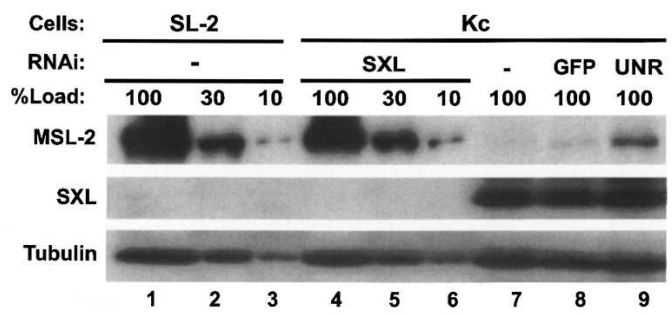

C

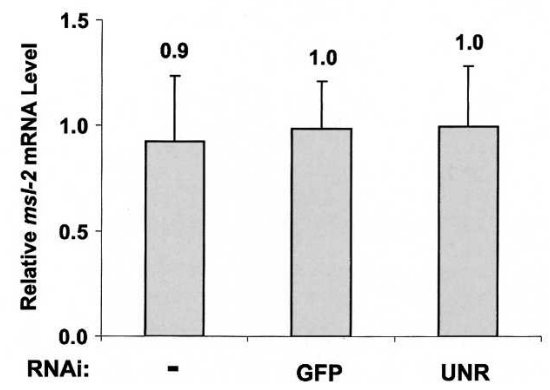

Figure 6. UNR is required for translational repression of endogenous msl-2 mRNA in Kc cells. (A) Levels of UNR, SXL, and $\alpha$-tubulin protein in whole-cell lysates were measured by immunoblotting. Mock RNAi SL-2 cells (lanes 1-3), mock RNAi Kc cells (lanes 4-6), or Kc cells treated with dsRNAs targeting EGFP (lane 7), SXL (lane 8), or UNR (lane 9). (B) Extracts from $A$ were analyzed for MSL-2, SXL, and $\alpha$-tubulin protein levels by immunoblotting. (Lanes 1-3) Untreated SL-2 cells. (Lanes 4-6) SXL dsRNA-treated Kc cells. (Lane 7) Untreated Kc cells. (Lane 8) Kc cells treated with dsRNAs targeting GFP. (Lane 9) Kc cells treated with dsRNAs targeting UNR. Blots shown are representative of multiple blots analyzing samples from three independent RNAi experiments. $(C)$ Levels of endogenous msl-2 mRNA in samples from Kc cells treated with the indicated dsRNAs were analyzed by qPCR. Average values and standard deviations in four independent RNAi experiments are shown.

How does UNR recruited by SXL to the 3' UTR interfere with translation initiation at the mRNA $5^{\prime}$ end? Presumably the SXL/UNR corepressor complex interacts with factors that affect small ribosomal subunit recruitment. This interaction might require direct participation of SXL, or SXL might serve only to recruit UNR to the $3^{\prime}$ UTR. Similarly, UNR might directly contact factors affecting small subunit recruitment, or may do so through additional bridging factors as part of a larger "corepressor assembly". Our biochemical approach identified factors in addition to UNR that specifically copurify with the repressed mRNP (Fig. 1B,C; Table 1). Interestingly, UNR is the only one of the copurified proteins that displays significant corepressor activity when assayed by RNAi in Kc cells (data not shown).

Since msl-2 mRNA repression functions in the absence of a $5^{\prime} \mathrm{m}^{7} \mathrm{GpppN}$ cap structure (Gebauer et al. 1999), translational regulatory proteins like Cup (Wilhelm et al. 2003; Nelson et al. 2004) or d4EHP (Cho et al. 2005) are unlikely to be the molecular targets of repression by the $3^{\prime}$-UTR complex. A candidate target is Drosophila PABP, since mammalian PABP interacts with UNR (Chang et al. 2004), and promotes small ribosomal subunit binding to the mRNA (Kahvejian et al. 2005). Although msl-2 translational inhibition does not require a poly(A) tail (Gebauer et al. 1999), PABP appears to have a critical function in initiation that is independent of the poly(A) tail (Kahvejian et al. 2005), raising the possibility that UNR might nevertheless interfere with PABP-mediated recruitment of the small ribosomal subunit to msl-2 mRNA. Future studies will aim to determine the mechanism by which SXL and UNR bound at the $3^{\prime}$ end of msl-2 mRNA block translation initiation at the $5^{\prime}$ end.

\section{Implications of SXL imparting sex-specific function} to UNR

Consistent with a general role as a regulator of dosage compensation, UNR mRNA expression is ubiquitous throughout Drosophila development (Arbeitman et al. 2002). Interestingly, UNR protein is expressed at similar levels in both male and female cells in culture (Fig. 4A) and in flies (Abaza et al. 2006), but only interacts with msl-2 mRNA to modulate its translation when SXL is present. Thus, SXL imparts a sex-specific, mRNA-specific translational repressor function to UNR (Fig. 7). Sex-specific modulation of UNR function by SXL is presumably crucial for dosage compensation, which would be compromised if the abundant UNR protein in males were able to inhibit msl-2 mRNA translation.

Sex-specific function at the cellular and organismal level can also be viewed as context-specific function at the molecular level, with SXL acting as a context-specific modulator of UNR function. The hypothesis that UNR function is modulated by molecular context is supported by the previously determined functions of mammalian UNR, which involve different protein-interaction partners, in the context of different RNA sequence elements (Hunt et al. 1999; Boussadia et al. 2003; Chen and Shyu 2003; Mitchell et al. 2003; Chang et al. 2004). Indeed, the previously reported role for mammalian UNR as a translational activator of cellular and viral IRESes made it a rather unexpected candidate for a translational corepressor. Our data identify the first function for UNR in Drosophila, and demonstrate the surprising finding that UNR can also be a critical component of translational repression complexes, underscoring the importance of both protein and RNA context in modulation 
Figure 7. SXL imparts a novel sex- and mRNA-specific translational repressor function to UNR. A model for UNR's sexspecific role in translational regulation of MSL-2 synthesis for dosage compensation is shown. In female cells, SXL first recruits UNR to the 3' UTR of msl-2 mRNA. Subsequently, 3'-UTR-bound UNR, possibly in concert with SXL and/or other factors, acts as a translational corepressor, inhibiting recruitment of the small ribosomal subunit-containing $43 \mathrm{~S}$ preinitiation complex to the mRNA $5^{\prime}$ end. $43 \mathrm{~S}$ complexes that escape this primary translational block are challenged by the UNR-independent scanning block mediated by 5'-UTR-bound SXL (Beckmann et al. 2005). The dual inhibitory mechanisms combine to prevent toxic expression of MSL-2 in females. In male cells, where MSL-2 translation is essential for dosage compensation, UNR and msl-2 mRNA are both present at high levels. The absence of SXL prevents stable interaction of UNR with the msl-2 mRNA, allowing active msl-2 mRNA translation.

of UNR function in post-transcriptional control of gene expression.

Another notable difference between UNR-mediated translational repression and the UNR functions described previously is that in the former case UNR is the recruited protein, whereas in the latter cases, high-affinity interaction of UNR with an RNA element underlies subsequent recruitment of additional proteins by UNR. This distinction has two important implications for UNR function. First, UNR's potential regulatory targets are not confined to mRNAs with high-affinity binding sites for UNR. Second, context-specific modulators such as SXL can be expected to be key determinants of how UNR affects regulation of a particular mRNA. Detailed mechanistic and structural analysis will be essential to answer the intriguing question of how UNR can function as a translational activator in one molecular context, and a repressor in another.

Role of UNR-mediated repression of MSL-2 synthesis in female flies

UNR depletion in Kc cells causes a significant increase in MSL-2 protein to $\sim 20 \%$ of that in male SL-2 cells or SXL-depleted Kc cells (Fig. 6A,B). Clearly, SXL-dependent, UNR-independent inhibition mediated by the msl-2 5' UTR contributes to repression of MSL-2 protein synthesis (Fig. 4; Beckmann et al. 2005). We also observe that SXL promotes reduced endogenous msl-2 mRNA levels, but UNR does not (Fig. 6; Supplementary Fig. S1). Our results warrant interpretation in the context of previous studies of transgenic flies; females expressing msl-2 transgenes lacking the 3 '-UTR regulatory sequences produce detectable MSL-2 protein, but at a significantly lower level than males or females expressing transgenes with both $5^{\prime}$ - and $3^{\prime}$-UTR SXL-binding sites deleted. The lower level of MSL-2 protein made in $3^{\prime}$ UTR mutant females is nevertheless sufficient to promote DCC loading onto female X chromosomes (Bashaw and Baker 1995, 1997; Kelley et al. 1997). Therefore, at the organismal level, UNR, acting through the msl-2 mRNA 3' UTR, can be expected to make a significant contribution to robust repression of MSL-2 protein synthesis and prevention of deleterious activation of the Xchromosome dosage-compensation machinery in females.

\section{Materials and methods}

\section{Plasmids}

BSEF, 3'EF and derivatives have been described previously (Gebauer et al. 2003; Grskovic et al. 2003). Three box-b sequences, amplified from pGL-B5-Box-B (Gehring et al. 2003) by PCR, were introduced between NotI and HindIII sites in the 3' UTR of these RNAs. pHSP70-SXL and the msl-2- $\beta$-gal reporters have been described (Bashaw and Baker 1997). Renilla Luciferase (RLuc) was introduced between HindIII and XhoI in pCaSpeR-hs (S. Cohen, EMBL, Heidelberg, Germany). pAC5.1-lacZ (Fig. 5D) is commercially available (Invitrogen). Plasmids used as templates for RNase Protection Assay probes were either PCRIITOPO-rp49 (E. Izaurralde, EMBL, Heidelberg, Germany) or pBSII-KS with a lacZ fragment (HpaI-ClaI) inserted into the MCS (EcoRV-ClaI). Plasmids for dsRNA templates were obtained from the EMBL Genomics Core Facility BDGP clone collection, except pHSP70-SXL (see above) and EGFP (E. Izaurralde, EMBL). All constructs were verified by sequencing. Oligo sequences used to make box-B constructs are in the Supplemental Material.

In vitro transcription, translation, recombinant protein, and antibodies

RNAs for in vitro translation were synthesized as described (Gebauer et al. 1999). All mRNAs contained a 5' $\mathrm{m}^{7} \mathrm{GpppG}$ cap and a poly(A) tail of 73 nucleotides. Drosophila embryo extracts were prepared and cell-free translation reactions carried out as previously described (Gebauer et al. 1999). SXL protein and its derivatives were expressed in Escherichia coli as a GST fusion and purified as described previously (Grskovic et al. 2003). Polyclonal anti-SXL antibodies against amino acids 122-301 were raised in rabbits. $\lambda$-GST protein was kindly provided by Ulrike Bauer, Kevin Czaplinski, and Iain Mattaj (EMBL, Heidelberg, Germany). 
GRNA chromatography, sucrose gradients, and mass spectrometry

For purification of native translationally silenced RNPs from Drosophila embryo extracts, we adapted the previously described method (Czaplinski et al. 2005). RNAs (10 $\mu \mathrm{g})$ were mixed on ice with $80 \mu \mathrm{L}$ Drosophila embryo extract, either 60 $\mu \mathrm{g}$ of the dRBD4 SXL derivative (Grskovic et al. 2003) or the equivalent volume of Buffer D and translation reaction components (Gebauer et al. 1999) in a final volume of $200 \mu \mathrm{L}$. Reactions were incubated for $10 \mathrm{~min}$ at $25^{\circ} \mathrm{C}$, removed to ice and subsequently processed at $4^{\circ} \mathrm{C}$. One-hundred-fifty microliters of glutathione-Sepharose (Amerhsam) prebound to the $\lambda$-GST protein and $200 \mu \mathrm{L}$ of Binding Buffer (BB) were added, and samples were incubated for $1 \mathrm{~h}$ with end-over-end rotation, then washed three times with $1 \mathrm{~mL}$ of ice-cold BB. RNA-associated proteins were eluted by adding $40 \mu \mathrm{L} \mathrm{BB}$ and $1 \mu \mathrm{L}$ Bovine Pancreas RNase A (100 $\mu \mathrm{g} / \mathrm{mL}$ stock, Protease-free, Calbiochem) to the beads, and incubating at $30^{\circ} \mathrm{C}$ for $30 \mathrm{~min}$ with shaking. Eluates were resuspended in protein sample buffer, fractionated on $6 \%-15 \%$ sucrose gradient polyacrylamide gels and silver stained using conditions compatible with mass spectrometry (Shevchenko et al. 1996). A detailed protocol including composition of buffers is included as Supplemental Material.

For gradient purifications prior to GRNA chromatography, 25 $\mu \mathrm{g}$ of RNAs were incubated in $1 \mathrm{~mL}$ of in vitro translation reactions in the absence or presence of a 60x molar excess of dRBD4. Reactions were incubated for $15 \mathrm{~min}$ at $25^{\circ} \mathrm{C}$ and subsequently loaded on a $35-\mathrm{mL}$ continuous $5 \%-25 \%$ sucrose density gradient. After centrifugation at $16,100 \mathrm{rpm}$ for $17.5 \mathrm{~h}$, fractions were collected from the bottom. Fractions 9-17 of each gradient were pooled, mixed with an equal volume of BB, and used for GRNA chromatography as described above.

Mass spectrometric analysis of trypsin-digested peptides from relevant gel regions was performed on a quadrupole time of flight mass spectrometer (Q-TOF I, Waters) interfaced with a capillary HPLC (UltiMate, Dionex). Peptide assignments and data analysis were performed with Mascot (Perkins et al. 1999).

Cell culture, RNAi, transfections, and reporter activity assays

Cells were maintained at $25^{\circ} \mathrm{C}$ at densities between $1 \times 10^{6}$ and $6 \times 10^{6}$ cells $/ \mathrm{mL}$ in Schneider's Medium (GIBCO) supplemented with L-glutamine (GIBCO, $1.2 \mathrm{mM})$, penicillin/streptomycin (GIBCO, 1\% v/v), and 10\% FBS (Invitrogen). RNAi was performed in culture flasks in a modified version of published protocols (Worby et al. 2001; Buscaino et al. 2003). Briefly, cells were pelleted at low speed at room temperature, resuspended at $1.5 \times 10^{6}$ cells $/ \mathrm{mL}$ in Schneider's medium without FBS, and added directly to dsRNAs at a final concentration of $15 \mu \mathrm{g}$ RNA/ $\mathrm{mL}$. After $30-60 \mathrm{~min}$ at $25^{\circ} \mathrm{C}$, a $2 \times$ volume of supplemented Schneider's Medium was added. RNAi incubations prior to transfection or harvesting for analysis were from 6 to $11 \mathrm{~d}$, as this was necessary for strong UNR depletion. dsRNAs for RNAi were generated using the Megascript kit (Ambion) and purified from template and nucleotides with MegaClear (Ambion). Oligos used to amplify dsRNAs for RNAi appear in the Supplemental Material.

Transfections with Effectene (QIAGEN) were as recommended for Schneider cells with harvesting after $3 \mathrm{~d}$. Reporter DNA concentrations were verified to be in the assay linear range by testing dilutions of the $5^{\prime}+3^{\prime}$ mut reporter. For SL-2 transfections with pHSP70-SXL, the plasmid or empty vector control were used at a 4:1 ratio relative to the msl-2 reporters. $\beta$-gal and Rluc activities were measured with Galacto-Star (Tropix) or Renilla substrate (Promega), respectively, using a 96-well plate luminometer (Perkin-Elmer).

\section{Protein extracts and immunoblotting}

Cells were pelleted and resuspended in ice-cold lysis buffer (100 $\mathrm{mM} \mathrm{NaCl}, 0.1 \%$ Triton X-100), then SDS protein sample buffer (Ausubel et al. 1999) was added, and cells were incubated twice for $5 \mathrm{~min}$ at $95^{\circ} \mathrm{C}$, with vortexing between. Samples were spun $2 \mathrm{~min}$ at $14,000 \mathrm{rpm}$ in a microfuge. Total protein concentrations of supernatants were determined with the Bio-Rad Protein Assay reagent. Five micrograms or $10 \mu \mathrm{g}$ of extract were used for SDS-PAGE and transfer to nitrocellulose with the Bio-Rad Mini Protean system according to the manufacturer's instructions. Blocking and antibody incubations were in TBS-T + 5\% milk, except for UNR and MSL-2 antibodies, which were used in TBS-T without milk. Primary antibodies and dilutions were as follows: mouse anti- $\alpha$-Tub, 1:24,000 (Sigma); rabbit anti-SXL DHJ4 1:2500, (Hentze lab stock); rat anti-MSL-2, 1:500 (from P. Becker, Adolf Butenandt-Institute, Molecular Biology Unit, Ludwig-Maximilians University, Munich, Germany); rabbit anti-MSL-2 affinity purified, 1:300 (from M. Kuroda, Howard Hughes Medical Institute, Harvard-Partners Center for Genetics and Genomics, Brigham and Women's Hospital, and Department of Genetics, Harvard Medical School, Boston, MA); rat anti-MSL-1, 1:2000 (from A. Akhtar, Gene Expression Unit, EMBL, Heidelberg, Germany); rabbit anti-UNR, 1:500 (Abaza et al. 2006). HRP-conjugated secondary antibodies (Amersham) for the appropriate species were used at $1: 10,000$ (SXL/Tub) or 1: 2500 (MSL-2). Secondary detection of UNR was with Protein A Peroxidase Conjugate (PAP), 1:1000 (Sigma). Signal was visualized by Super Signal West Pico or Femto (for MSL-2) reagent (Pierce) and exposure to film.

\section{RNA preparation, DNase treatment, reverse-transcription}

Total RNA was prepared from cell pellets with Trizol (Invitrogen) according to the manufacturer's protocol. RNA for reverse transcription was first treated with RNase-free DNase RQ1 (Promega), and/or RNase-free DNase I (Roche). DNase-treated RNA (1-4 $\mu \mathrm{g})$ was reverse transcribed using random hexamer primers and SuperScript II (Invitrogen) according to the manufacturer's protocol. Samples were diluted $10-20 \times$ in water and 5 $\mu \mathrm{L}$ of these samples were used for qPCR. A control reaction omitting SuperScript II was performed for each sample and included in all qPCR analyses to confirm RNA dependence of the amplified cDNA products.

\section{RNase protection assays}

Probes for RPAs were synthesized from gel-purified linearized plasmids (BsmBI for 1acZ, NotI for rp49) using T3 and T7 RNA polymerase, respectively, and the Maxiscript kit (Ambion) with $\left[{ }^{32} \mathrm{P}\right] \mathrm{UTP}$ (Amersham). For rp49, unlabeled UTP was also included to reduce the specific activity of this probe by $\sim 20$ times. Free nucleotides were removed with Chromaspin-100 columns (BD Bioscience) and probes were verified to be $>90 \%$ full length by checking aliquots on a $6 \%$ TBE gel; $10 \mu \mathrm{g}$ of total RNA was analyzed with both probes simultaneously using the Hybspeed RPA kit (Ambion), following the manufacturer's protocol. Samples were separated on 6\% TBE gels, and dried gels were exposed to PhosphorImager screens (Molecular Dynamics) for imaging and quantification.

\section{$q P C R$}

qPCR was performed using the standard curve method and SYBR Green Chemistry on Applied Biosystems 7000 or 7500 SDS instruments. For a given RNAi experiment, all GFP control samples were assayed in parallel with corresponding SXL and UNR samples. Each sample was normalized to the appropriate internal standard (Rluc for lacZ, rp49 for msl-2, or GAPDH for 
roX RNAs and RNApol), and the average of the independent GFP RNAi samples within an RNAi experiment was set to 1.0. Values for SXL and UNR were calculated relative to this normalization, enabling comparison of relative changes across multiple RNAi experiments. Primer sequences appear in the Supplemental Material.

\section{Acknowledgments}

We thank Asifa Akhtar and members of her laboratory for reagents and helpful discussions; Elisa Izaurralde for Kc cells; Donna Arndt-Jovin for SF-4 cells; Peter Becker, Mitzi Kuroda, and John Lucchesi for anti-MSL-2 antibodies; Bruce Baker for reporter constructs; Kevin Czaplinski for advice and sharing reagents for GRNA chromatography; Vladimir Benes for clones and support for qPCR; and members of the Hentze laboratory for useful discussions. K.D. is the recipient of a Marie Curie Incoming International Fellowship from the EU under the Sixth Framework. This work was supported by a grant from the Deutsche Forschungsgemeinschaft (FOR426/HE1442/7-2 and 7-3) to M.W.H.

\section{References}

Abaza, I., Coll, O., Patalano, S., and Gebauer, F. 2006. Drosophila UNR is required for translational repression of malespecific-lethal 2 mRNA during regulation of X-chromosome dosage compensation. Genes \& Dev. (this issue).

Arbeitman, M.N., Furlong, E.E., Imam, F., Johnson, E., Null, B.H., Baker, B.S., Krasnow, M.A., Scott, M.P., Davis, R.W., and White, K.P. 2002. Gene expression during the life cycle of Drosophila melanogaster. Science 297: 2270-2275.

Ausubel, F.M., Brent, R., Kingston, R.E., Moore, D.D., Seidman, J.G., Smith, J.A., and Struhl, K. 1999. Short protocols in molecular biology. John Wiley \& Sons, Inc., New York.

Baker, B.S., Gorman, M., and Marin, I. 1994. Dosage compensation in Drosophila. Annu. Rev. Genet. 28: 491-521.

Bashaw, G.J. and Baker, B.S. 1995. The msl-2 dosage compensation gene of Drosophila encodes a putative DNA-binding protein whose expression is sex specifically regulated by Sexlethal. Development 121: 3245-3258.

- 1997. The regulation of the Drosophila msl-2 gene reveals a function for Sex-lethal in translational control. Cell 89: 789-798.

Beckmann, K., Grskovic, M., Gebauer, F., and Hentze, M.W. 2005. A dual inhibitory mechanism restricts msl-2 mRNA translation for dosage compensation in Drosophila. Cell 122: 529-540.

Bell, L.R., Maine, E.M., Schedl, P., and Cline, T.W. 1988. Sexlethal, a Drosophila sex determination switch gene, exhibits sex-specific RNA splicing and sequence similarity to RNA binding proteins. Cell 55: 1037-1046.

Belote, J.M. and Lucchesi, J.C. 1980. Male-specific lethal mutations of Drosophila melanogaster. Genetics 96: 165-186.

Birchler, J.A., Riddle, N.C., Auger, D.L., and Veitia, R.A. 2005. Dosage balance in gene regulation: Biological implications. Trends Genet. 21: 219-226.

Boussadia, O., Amiot, F., Cases, S., Triqueneaux, G., JacqueminSablon, H., and Dautry, F. 1997. Transcription of unr (upstream of $\mathrm{N}$-ras) down-modulates $\mathrm{N}$-ras expression in vivo. FEBS Lett. 420: 20-24.

Boussadia, O., Niepmann, M., Creancier, L., Prats, A.C., Dautry, F., and Jacquemin-Sablon, H. 2003. Unr is required in vivo for efficient initiation of translation from the internal ribosome entry sites of both rhinovirus and poliovirus. $J$.
Virol. 77: 3353-3359.

Brown, E.C. and Jackson, R.J. 2004. All five CDSs of unr (upstream of N-ras) are required for stimulation of human rhinovirus RNA translation. J. Gen. Virol. 85: 2279-2287.

Burtis, K.C. and Baker, B.S. 1989. Drosophila doublesex gene controls somatic sexual differentiation by producing alternatively spliced mRNAs encoding related sex-specific polypeptides. Cell 56: 997-1010.

Buscaino, A., Kocher, T., Kind, J.H., Holz, H., Taipale, M., Wagner, K., Wilm, M., and Akhtar, A. 2003. MOF-regulated acetylation of MSL-3 in the Drosophila dosage compensation complex. Mol. Cell 11: 1265-1277.

Chang, T.C., Yamashita, A., Chen, C.Y., Yamashita, Y., Zhu, W., Durdan, S., Kahvejian, A., Sonenberg, N., and Shyu, A.B. 2004. UNR, a new partner of poly(A)-binding protein, plays a key role in translationally coupled mRNA turnover mediated by the c-fos major coding-region determinant. Genes \& Dev. 18: 2010-2023.

Chen, C.Y. and Shyu, A.B. 2003. Rapid deadenylation triggered by a nonsense codon precedes decay of the RNA body in a mammalian cytoplasmic nonsense-mediated decay pathway. Mol. Cell. Biol. 23: 4805-4813.

Cho, P.F., Poulin, F., Cho-Park, Y.A., Cho-Park, I.B., Chicoine, J.D., Lasko, P., and Sonenberg, N. 2005. A new paradigm for translational control: Inhibition via $5^{\prime}-3^{\prime}$ mRNA tethering by Bicoid and the eIF4E cognate 4EHP. Cell 121: 411-423.

Cline, T.W. 1978. Two closely linked mutations in Drosophila melanogaster that are lethal to opposite sexes and interact with daughterless. Genetics 90: 683-698.

Cline, T.W. and Meyer, B.J. 1996. Vive la difference: Males vs females in flies vs worms. Annu. Rev. Genet. 30: 637-702.

Czaplinski, K., Kocher, T., Schelder, M., Segref, A., Wilm, M., and Mattaj, I.W. 2005. Identification of 40LoVe, a Xenopus hnRNP D family protein involved in localizing a TGF- $\beta$ related mRNA during oogenesis. Dev. Cell 8: 505-515.

Dolfini, S. 1971. Karyotype polymorphism in a cell population of Drosophila melanogaster cultured in vitro. Chromosoma 33: 196-208.

Doniger, J., Landsman, D., Gonda, M.A., and Wistow, G. 1992. The product of unr, the highly conserved gene upstream of $\mathrm{N}$-ras, contains multiple repeats similar to the cold-shock domain (CSD), a putative DNA-binding motif. New Biol. 4: 389-395.

Echalier, G. 1971. II. Established diploid cell lines of Drosophila melanogster as potential material for the study of genetics in somatic cells. Curr. Top. Microbiol. Immunol. 55: 220-227.

Evans, J.R., Mitchell, S.A., Spriggs, K.A., Ostrowski, J., Bomsztyk, K., Ostarek, D., and Willis, A.E. 2003. Members of the poly $(\mathrm{rC})$ binding protein family stimulate the activity of the c-myc internal ribosome entry segment in vitro and in vivo. Oncogene 22: 8012-8020.

Franke, A. and Baker, B.S. 1999. The rox1 and rox2 RNAs are essential components of the compensasome, which mediates dosage compensation in Drosophila. Mol. Cell 4: $117-$ 122.

Gebauer, F., Merendino, L., Hentze, M.W., and Valcarcel, J. 1998. The Drosophila splicing regulator sex-lethal directly inhibits translation of male-specific-lethal 2 mRNA. RNA 4: 142-150.

Gebauer, F., Corona, D.F., Preiss, T., Becker, P.B., and Hentze, M.W. 1999. Translational control of dosage compensation in Drosophila by Sex- lethal: Cooperative silencing via the $5^{\prime}$ and 3' UTRs of msl-2 mRNA is independent of the poly(A) tail. $E M B O$ J. 18: 6146-6154.

Gebauer, F., Grskovic, M., and Hentze, M.W. 2003. Drosophila sex-lethal inhibits the stable association of the $40 \mathrm{~S}$ ribo- 
somal subunit with msl-2 mRNA. Mol. Cell 11: 1397-1404. Gehring, N.H., Neu-Yilik, G., Schell, T., Hentze, M.W., and Kulozik, A.E. 2003. Y14 and hUpf3b form an NMD-activating complex. Mol. Cell 11: 939-949.

Gilfillan, G.D., Dahlsveen, I.K., and Becker, P.B. 2004. Lifting a chromosome: Dosage compensation in Drosophila melanogaster. FEBS Lett. 567: 8-14.

Graumann, P.L. and Marahiel, M.A. 1998. A superfamily of proteins that contain the cold-shock domain. Trends Biochem. Sci. 23: 286-290.

Grosset, C., Chen, C.Y., Xu, N., Sonenberg, N., Jacquemin-Sablon, H., and Shyu, A.B. 2000. A mechanism for translationally coupled mRNA turnover: Interaction between the poly(A) tail and a c-fos RNA coding determinant via a protein complex. Cell 103: 29-40.

Grskovic, M., Hentze, M.W., and Gebauer, F. 2003. A co-repressor assembly nucleated by Sex-lethal in the 3'UTR mediates translational control of Drosophila msl-2 mRNA. EMBO J. 22: $5571-5581$.

Hilfiker, A., Yang, Y., Hayes, D.H., Beard, C.A., Manning, J.E., and Lucchesi, J.C. 1994. Dosage compensation in Drosophila: The X-chromosomal binding of MSL-1 and MLE is dependent on Sxl activity. EMBO J. 13: 3542-3550.

Hilfiker, A., Hilfiker-Kleiner, D., Pannuti, A., and Lucchesi, J.C. 1997. mof, a putative acetyl transferase gene related to the Tip60 and MOZ human genes and to the SAS genes of yeast, is required for dosage compensation in Drosophila. EMBO $\mathrm{I}$. 16: 2054-2060.

Hunt, S.L., Hsuan, J.J., Totty, N., and Jackson, R.J. 1999. unr, a cellular cytoplasmic RNA-binding protein with five coldshock domains, is required for internal initiation of translation of human rhinovirus RNA. Genes \& Dev. 13: 437-448.

Jacquemin-Sablon, H., Triqueneaux, G., Deschamps, S., le Maire, M., Doniger, J., and Dautry, F. 1994. Nucleic acid binding and intracellular localization of unr, a protein with five cold shock domains. Nucleic Acids Res. 22: 2643-2650.

Kahvejian, A., Svitkin, Y.V., Sukarieh, R., M’Boutchou, M.N., and Sonenberg, N. 2005. Mammalian poly(A)-binding protein is a eukaryotic translation initiation factor, which acts via multiple mechanisms. Genes \& Dev. 19: 104-113.

Kelley, R.L., Solovyeva, I., Lyman, L.M., Richman, R., Solovyev, V., and Kuroda, M.I. 1995. Expression of msl-2 causes assembly of dosage compensation regulators on the $\mathrm{X}$ chromosomes and female lethality in Drosophila. Cell 81: 867-877.

Kelley, R.L., Wang, J., Bell, L., and Kuroda, M.I. 1997. Sex lethal controls dosage compensation in Drosophila by a non-splicing mechanism. Nature 387: 195-199.

Meller, V.H., Wu, K.H., Roman, G., Kuroda, M.I., and Davis, R.L. 1997. roX1 RNA paints the X chromosome of male Drosophila and is regulated by the dosage compensation system. Cell 88: 445-457.

Mitchell, S.A., Spriggs, K.A., Coldwell, M.J., Jackson, R.J., and Willis, A.E. 2003. The Apaf-1 internal ribosome entry segment attains the correct structural conformation for function via interactions with PTB and unr. Mol. Cell 11: 757771.

Nelson, M.R., Leidal, A.M., and Smibert, C.A. 2004. Drosophila Cup is an eIF4E-binding protein that functions in Smaugmediated translational repression. EMBO J. 23: 150-159.

Nusinow, D.A. and Panning, B. 2005. Recognition and modification of seX chromosomes. Curr. Opin. Genet. Dev. 15: 206-213.

Palmer, M.J., Richman, R., Richter, L., and Kuroda, M.I. 1994. Sex-specific regulation of the male-specific lethal-1 dosage compensation gene in Drosophila. Genes \& Dev. 8: 698-706.

Penalva, L.O. and Sanchez, L. 2003. RNA binding protein sex- lethal (Sxl) and control of Drosophila sex determination and dosage compensation. Microbiol. Mol. Biol. Rev. 67: 343359.

Perkins, D.N., Pappin, D.J., Creasy, D.M., and Cottrell, J.S. 1999. Probability-based protein identification by searching sequence databases using mass spectrometry data. Electrophoresis 20: 3551-3567.

Ryner, L.C. and Baker, B.S. 1991. Regulation of doublesex premRNA processing occurs by 3 '-splice site activation. Genes \& Dev. 5: 2071-2085.

Shevchenko, A., Wilm, M., Vorm, O., and Mann, M. 1996. Mass spectrometric sequencing of proteins silver-stained polyacrylamide gels. Anal. Chem. 68: 850-858.

Tinton, S.A., Schepens, B., Bruynooghe, Y., Beyaert, R., and Cornelis, S. 2005. Regulation of the cell-cycle-dependent internal ribosome entry site of the PITSLRE protein kinase: Roles of Unr (upstream of N-ras) protein and phosphorylated translation initiation factor eIF-2 $\alpha$. Biochem. J. 385: 155-163.

Uchida, N., Uenoyama, T., and Oishi, K. 1981. Studies on the sex-specific lethals of Drosophila melanogaster. III. A third chromosome male-specific lethal mutant. Ipn. I. Genet. 56: 523-527.

Wilhelm, J.E., Hilton, M., Amos, Q., and Henzel, W.J. 2003. Cup is an eIF4E binding protein required for both the translational repression of oskar and the recruitment of Barentsz. J. Cell. Biol. 163: 1197-1204.

Worby, C.A., Simonson-Leff, N., and Dixon, J.E. 2001. RNA interference of gene expression (RNAi) in cultured Drosophila cells. Sci. STKE 2001: PL1.

Zhou, S., Yang, Y., Scott, M.J., Pannuti, A., Fehr, K.C., Eisen, A., Koonin, E.V., Fouts, D.L., Wrightsman, R., Manning, J.E., et al. 1995. Male-specific lethal 2, a dosage compensation gene of Drosophila, undergoes sex-specific regulation and encodes a protein with a RING finger and a metallothionein-like cysteine cluster. $E M B O$ J. 14: 2884-2895. 


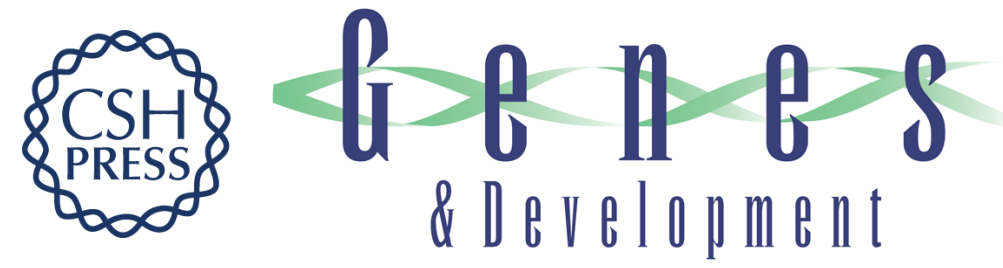

\section{Sex-lethal imparts a sex-specific function to UNR by recruiting it to the msl-2 mRNA 3' UTR: translational repression for dosage compensation}

Kent Duncan, Marica Grskovic, Claudia Strein, et al.

Genes Dev. 2006, 20:

Access the most recent version at doi:10.1101/gad.371406

Supplemental http://genesdev.cshlp.org/content/suppl/2006/01/18/20.3.368.DC1

Material

References This article cites 53 articles, 17 of which can be accessed free at: http://genesdev.cshlp.org/content/20/3/368.full.html\#ref-list-1

License

Email Alerting Receive free email alerts when new articles cite this article - sign up in the box at the top Service right corner of the article or click here.

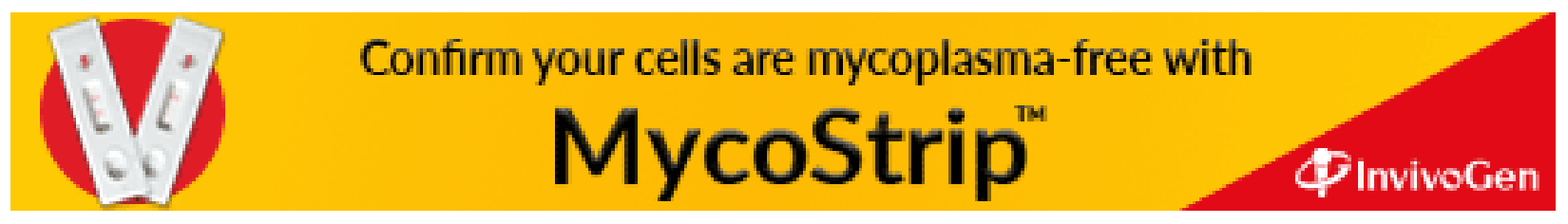

